\title{
TELECAREER: ANTECEDENTS AND CONSEQUENCES OF STRATEGIC CAREER BEHAVIOURS ON IBERIAN TELEWORKERS
}

\author{
Joana Carneiro Pinto \\ School of Human Sciences, Catholic University of Portugal (Portugal)
}

\begin{abstract}
This paper aims to present the state of the art, objectives, methodology and expected results of a project that investigates the nature, causes and consequences of the use of strategic career management behaviours in an Iberian sample of teleworking adults. Specifically, our purpose is to analyze the strategic behaviours - authenticity, balance and challenge - according to the Kaleidoscopic Career Model developed by Sullivan and Mainiero (2008). The role of self-efficacy beliefs, the desire for career control, and perceived organizational support, as antecedents of those career behaviours, will be assessed, as well, as the consequences of their use on perceived career control, objective and subjective career success, and career satisfaction. The aim is to develop an explanatory model of career management for Iberian teleworkers, with implications for the design of human resource development programmes in organisational contexts. It is an innovative project on the international scenario, by the target population on which it focuses, but also by the combination of the selected career variables.
\end{abstract}

Keywords: Strategic career behaviours, human resources management, teleworkers, empirical model.

\section{State of the art}

Over the past fifty years, behaviours and attitudes of personal control over one's career have been considered a consequence of vicissitudes affecting the world in general, and organizational life in particular. Several authors have argued that these behavioural dynamics should be seen as normative in relation to working life, since they express the progressive desire for personal control over career outcomes (King, 2000; Sullivan \& Mainiero, 2008; Viannen, et al., 2008). In this sense, the interest for the study of strategic behaviours on career goals has been increasing (e.g., Greenhaus, et al., 2010; Kossek, et al, 1998).

According to the Kaleidoscopic Career Model (Sullivan \& Mainiero, 2008), there are three strategic career behaviours: (i) authenticity, alignment between own values and those of the organization, (ii) balance, between professional and non-professional responsibilities; and, (iii) challenge, stimulus at work and career progression opportunities. Each worker, throughout his/her career/life, invests more or less in each of these behaviours, depending on the career objectives he/she has defined. In relation to teleworkers, these behaviours are expected to be even more pertinent, given the proactive and autonomous role expected from them, not only in the redefinition of their professional roles and responsibilities, but also in terms of their career decision-making (Raghuram, Wiesenfeld \& Garud, 2003).

Strategic career behaviours have been associated with desired personal and professional results, such as the perception of success (Sturges, et al, 2002), the perception of control over career goals (King, 2000), wage increase (Lau \& Pang, 2000; Raabe, Frese, \& Beehr, 2007), career/work satisfaction (King, 2000; Lent \& Brown, 2006; Raabe, et al, 2007), and life satisfaction (King, 2000). Research also indicates that socio-cognitive factors (e.g., beliefs of self-efficacy, perception of support and barriers to achieving goals; King, 2000; Kossek, et al., 1998; Lent \& Brown, 2006; Raghuram, et al, 2003), and perceived organizational support (e.g., Desrosiers, 2001) are motivators for strategic career action.

Despite this important set of studies, there is still a narrow understanding about the relationships between these variables. Moreover, the conclusions from these studies have applicability, mostly, in "traditional" workers. Although official statistics do not exist, with the lockdown due to the Corona virus, it is estimated, that in Portugal and Spain, a great number of workers have been developing their activity through teleworking in the past few months. And, it is possible that, in a near future, some companies will adhere more easily to this type of work regime. But, teleworkers, in general, believe that teleworking impairs their advancement towards the desired professional goals (e.g., McCloskey \& Igbaria, 2003). Human resources departments will benefit from the findings of this project, as they will be able to develop personal career development programs that give workers back a sense of power and control over their career goals and thus stimulate greater adherence to the reality of telework. 


\section{Objectives}

This study aims to characterise the nature of career management strategies and to develop and empirically test an integrative model that explains the causes and consequences of the use of such strategies for Iberian teleworking adults. In this sense, the following specific objectives are pursued: (a) To characterize the use of behavioural processes (authenticity, balance and challenge) of career management by Iberian teleworking adults; (b) To test existing causal relationships between beliefs of self-efficacy, desire for control over career goals, and perceived organisational support, and the use of career management strategies; (c) To test existing causal relationships between the use of career management strategies and perceived control over career, objective and subjective career success and career satisfaction; (d) To test the impact of sociodemographic variables of the teleworking adults on the causes, behaviours, and consequences of using kaleidoscopic career management strategies; (e) To derive implications of the data for the development of theory on personal career control and to outline methods of promoting career strategies for teleworkers, considering that the idea of "out of sight" may mean "out of mind" in terms of career progression, is seen as one of the main reasons for professionals to be resistant to joining the telework regime.

\section{Methodological work plan}

The implementation of the work programme will take place in three phases.

1st phase: Literature review to update knowledge that will focus on the use of behavioural processes aimed at influencing career results, using referential and full text bases, with access to national and international studies. And, contact, information sharing, and associated work, with international and national researchers who can give more contributions to this research.

2nd phase: Conducting the empirical study, i.e. the study of the measurement model, by collecting data from an Iberian sample of teleworking adults. According to the defined hypothetical model, three antecedent variables contribute to the use of the strategic behaviours of the kaleidoscopic career model. Thus, it is expected that beliefs of self-efficacy (a) desire for control over career goals (b) and perceived organizational support (c) determine the three career management behaviours (authenticity, balance and challenge). But it is also expected that perceived organizational support (d) will influence self-efficacy beliefs and career satisfaction (e). As well, self-efficacy beliefs are expected to influence subjective career success (f). In turn, it is expected that the use of authenticity, balance, and career challenge behaviours will determine four consequential ones, namely perceived career control (g), objective career success (h), subjective career success (i), and career satisfaction (j). Amongst these, perceived career progress influences career satisfaction $(\mathrm{k})$, and objective career success influences both perceived career progress (l) and career satisfaction (m). The possibility of socio-demographic variables affecting the nature, causes and consequences of the use of this type of career strategies is also anticipated (see figure 1). The evaluation of the variables will be carried out using questionnaires (quantitative data). In addition to the measures, information regarding the research and the response procedure will be provided and participants will be informed about the ethical procedures. The evaluation protocol will be placed on an international dissemination platform for studies to facilitate the data collection process.

Figure 1. Kaleidoscopic Career Model: antecedents e consequences on teleworkers.

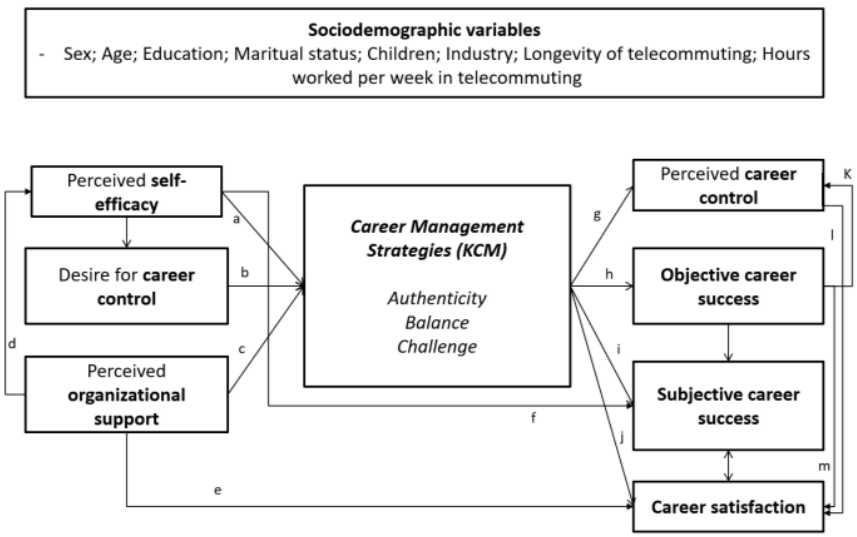

3rd phase: The results of the measurement model are analysed, interpreted, and disseminated. Data will be entered into a database and processed through Structural Equation Modelling (SEM) procedures for the purpose of testing the hypothesised conceptual model. We will analyse the significance of the hypothesised trajectories and assess the overall quality of the model's adjustment to data. The results obtained will contribute to the expansion of the theory of personal control in the career, with 
implications for the design of methods to promote career strategies in organizational contexts, specifically oriented to Iberian teleworkers. In general, the aim will be to contribute to the identification and creation of strategies through which HR departments can support these workers to acquire, train, and develop a set of skills that increase the probability of achieving their career/life goals even in a telework situation.

\section{Expected results}

Despite the important set of studies that we present in the state of art, there is still a narrow understanding about the relationships between the variables included in this study. Moreover, the conclusions from these studies have applicability, mostly, in "traditional" workers. Although official statistics do not exist, with the lockdown due to the coronavirus, it is estimated, that in Portugal and Spain, a great number of workers (about four out of 10) have been developing their activity through teleworking in the past few months. And it is possible that, in a near future, some companies will adhere more easily to this type of work regime. The previous prejudice associated with teleworking has changed due to the pandemic. And, in an economy that will certainly be very fragile, telework may give the necessary boost, within what is possible, to the economy. But, teleworkers, in general, believe that teleworking impairs their advancement towards the desired professional goals. This project will be immensely useful in understanding how people use their personal resources so that they can continue actively in career development. This has never been done more intensely and actively than in these times. With this project we can inform those who work with workers (Human Resources Departments), to promote goals aligned with a more satisfactory career management, and capable of empowering workers in their decision making. On the other hand, from this restructuring of the world of work and telework, new career opportunities arise within the career counselling itself, new challenges, which can only be mitigated when investigated.

\section{References}

Desrosiers, E. I. (2001). Telework and work attitudes: The relationship between telecommuting and employee job satisfaction, organizational commitment, perceived organizational support, and perceived co-worker support.

Greenhaus, J. H., Callanan, G. A., \& Godshalk, V. M. (2010). Career management. Sage.

King, Z. M. E. (2000). The development and initial test of a theory of career self-management (Doctoral dissertation, Birkbeck (University of London).

Kossek, E. E., Roberts, K., Fisher, S., \& Demarr, B. (1998). Career self-management: A quasi-experimental assessment of the effects of a training intervention. Personnel Psychology, 51(4), 935-960.

Lau, A., \& Pang, M. (2000). Career strategies to strengthen graduate employees' employment position in the Hong Kong labour market. Education+ Training.

Lent, R. W., \& Brown, S. D. (2006). Integrating person and situation perspectives on work satisfaction: A social-cognitive view. Journal of Vocational Behavior, 69(2), 236-247.

McCloskey, D. W., \& Igbaria, M. (2003). Does" out of sight" mean" out of mind"? An empirical investigation of the career advancement prospects of telecommuters. Information Resources Management Journal (IRMJ), 16(2), 19-34.

Raabe, B., Frese, M., \& Beehr, T. A. (2007). Action regulation theory and career self-management. Journal of Vocational Behavior, 70(2), 297-311.

Raghuram, S., Wiesenfeld, B., \& Garud, R. (2003). Technology enabled work: The role of self-efficacy in determining telecommuter adjustment and structuring behavior. Journal of Vocational Behavior, 63(2), 180-198.

Sturges, J., Guest, D., Conway, N., \& Davey, K. M. (2002). A longitudinal study of the relationship between career management and organizational commitment among graduates in the first ten years at work. Journal of Organizational Behavior: The International Journal of Industrial, Occupational and Organizational Psychology and Behavior, 23(6), 731-748.

Sullivan, S. E., \& Mainiero, L. (2008). Using the kaleidoscope career model to understand the changing patterns of women's careers: Designing HRD programs that attract and retain women. Advances in Developing Human Resources, 10(1), 32-49.

Van Vianen, A. E., De Pater, I. E., \& Preenen, P. T. (2008). Career management: taking control of the quality of work experiences. In International handbook of career guidance (pp. 283-301). Springer, Dordrecht. 